Survey

\title{
The multi-level perspective on sustainability transitions: Responses to seven criticisms
}

\author{
Frank W. Geels* \\ SPRU, Science and Technology Policy Research, University of Sussex, United Kingdom
}

\section{A R T I C L E I N F O}

\section{Article history:}

Received 24 November 2010

Received in revised form 15 February 2011

Accepted 18 February 2011

\section{Keywords:}

Transitions

Sustainable development

Multi-level perspective

Response to critics

\begin{abstract}
A B S T R A C T
The multi-level perspective (MLP) has emerged as a fruitful middle-range framework for analysing socio-technical transitions to sustainability. The MLP also received constructive criticisms. This paper summarises seven criticisms, formulates responses to them, and translates these into suggestions for future research. The criticisms relate to: (1) lack of agency, (2) operationalization of regimes, (3) bias towards bottom-up change models, (4) epistemology and explanatory style, (5) methodology, (6) socio-technical landscape as residual category, and (7) flat ontologies versus hierarchical levels.
\end{abstract}

(c) 2011 Elsevier B.V. All rights reserved.

\section{Transitions to sustainability}

Contemporary environmental problems, such as climate change, loss of biodiversity, and resource depletion (clean water, oil, forests, fish stocks, etc.) present formidable societal challenges. Addressing these problems requires factor 10 or more improvements in environmental performance which can only be realized by deep-structural changes in transport, energy, agri-food and other systems (Elzen et al., 2004; Van den Bergh and Bruinsma, 2008; Grin et al., 2010). These systemic changes are often called 'socio-technical transitions', because they involve alterations in the overall configuration of transport, energy, and agri-food systems, which entail technology, policy, markets, consumer practices, infrastructure, cultural meaning and scientific knowledge (Elzen et al., 2004; Geels, 2004). These elements are reproduced, maintained and transformed by actors such as firms and industries, policy makers and politicians, consumers, civil society, engineers and researchers. Transitions are therefore complex and long-term processes comprising multiple actors.

\footnotetext{
* Tel.: +44 01273678171 .

E-mail address: f.w.geels@sussex.ac.uk
} 
Transitions towards sustainability have some special characteristics that make them different, in certain respects, from many (though not all) historical transitions. First, sustainability transitions are goal-oriented or 'purposive' (Smith et al., 2005) in the sense of addressing persistent environmental problems, whereas many historical transitions were 'emergent' (e.g. entrepreneurs exploring commercial opportunities related to new technologies). Private actors have limited incentives to address sustainability transitions, because the goal is related to a collective good ('sustainability'), which implies free rider problems and prisoner's dilemmas. Public authorities and civil society will be crucial to address public goods and internalize negative externalities, to change economic frame conditions, and to support 'green' niches (Elzen et al., 2011). Because sustainability is an ambiguous and contested concept, there will be disagreement and debate about the directionality of sustainability transitions (Stirling, 2009), the (dis)advantages of particular solutions and the most appropriate policy instruments or packages.

A second characteristic that makes sustainability transitions unique is that most 'sustainable' solutions do not offer obvious user benefits (because sustainability is a collective good), and often score lower on price/performance dimensions than established technologies. It is therefore unlikely that environmental innovations will be able to replace existing systems without changes in economic frame conditions (e.g., taxes, subsidies, regulatory frameworks). These changes will require changes in policies, which entails politics and power struggles, because vested interests will try to resist such changes.

A third characteristic relates to the empirical domains where sustainability transitions are most needed, such as transport, energy and agri-food. These domains are characterized by large firms (e.g., car manufacturers, electric utilities, oil companies, food processing companies, supermarkets) that possess 'complementary assets' such as specialized manufacturing capability, experience with largescale test trials, access to distribution channels, service networks, and complementary technologies (Rothaermel, 2001). These complementary assets give incumbent firms strong positions vis-a-vis pioneers that often first develop environmental innovations. Although large incumbent firms will probably not be the initial leaders of sustainability transitions, their involvement might accelerate the breakthrough of environmental innovations if they support these innovations with their complementary assets and resources. This would, however, require a strategic reorientation of incumbents who presently still defend existing systems and regimes.

These considerations imply that sustainability transitions are necessarily about interactions between technology, policy/power/politics, economics/business/markets, and culture/discourse/public opinion. Researchers therefore need theoretical approaches that address, firstly, the multi-dimensional nature of sustainability transitions, and, secondly, the dynamics of structural change. With regard to structural change the problem is that many existing (unsustainable) systems are stabilized through various lock-in mechanisms, such as scale economies, sunk investments in machines, infrastructures and competencies. Also institutional commitments, shared beliefs and discourses, power relations, and political lobbying by incumbents stabilize existing systems (Unruh, 2000). Additionally, consumer lifestyles and preferences may have become adjusted to existing technical systems. These lock-in mechanisms create path dependence and make it difficult to dislodge existing systems. So, the core analytical puzzle is to understand how environmental innovations emerge and how these can replace, transform or reconfigure existing systems.

This paper is about one particular approach, namely the multi-level perspective (MLP). On both of the above aspects (multi-dimensionality and structural change), the MLP goes beyond studies of single technologies (such as wind turbines, biofuels, fuel cells, and electric vehicles), which dominate the literature on environmental innovation. The technological innovation system approach (Hekkert et al., 2007) is multi-dimensional (although cultural and demand side aspects are under-developed), but does not address structural change (how emerging innovations struggle against existing systems). The disruptive innovation (Christensen, 1997) and technological discontinuity (Anderson and Tushman, 1990) literatures do look at interactions between new entrants and incumbents, but tend to focus only on technology and market dimensions. Both approaches also have a technology-push character, with 'eras of incremental change' being punctuated by new technologies into 'eras of ferment'. While the MLP allows for technology-push substitution as one kind of transition pattern, it also distinguishes other transition patterns in which regime destabilisation precedes technical substitution (see Section 
"Bias towards bottom-up change models" below). Long-wave theory on techno-economic paradigm (TEP) shifts (Freeman and Perez, 1988) is multi-dimensional and addresses structural change. TEPs refer to configurations of pervasive technologies, methods of productions, economic structures, institutions and beliefs that are stable for long periods. Early explanations of TEP shifts (Freeman and Perez, 1988) had deterministic overtones with techno-economic forces doing the initial acting and the socioinstitutional framework doing the subsequent reacting. Freeman and Louçă (Freeman and Louçă, 2001) subsequently distinguished five interacting sub-systems (science, technology, economy, politics and culture), and emphasized the alignments between sub-system dynamics: "It is essential to study both the relatively independent development of each stream of history and their interdependencies, their loss of integration, and their reintegration" (Freeman and Louçă, 2001:127). While this conceptual refinement brings TEP closer to the MLP, there remains a difference in scope, with TEP focusing on entire economies and MLP focusing on concrete energy, transport, agri-good systems etc. TEP-work therefore gives more attention to aggregate processes, while MLP-work focuses in more detail on the various groups, their strategies, resources, beliefs and interactions.

While there are various approaches to transitions, with different strengths and weaknesses, the remainder of this paper focuses on the MLP. The emergence of the MLP as a fruitful approach has been accompanied by various criticisms. This paper aims to respond to these criticisms, qualify them, and, where possible, translate them into productive suggestions for future research. The paper is organized as follows. Section "The multi-level perspective on socio-technical transitions" briefly describes the MLP. Section "Criticisms, responses, and suggestions for future research" addresses seven types of criticisms. Section "Concluding comments" concludes.

\section{The multi-level perspective on socio-technical transitions}

The multi-level perspective (MLP) is a middle-range theory that conceptualizes overall dynamic patterns in socio-technical transitions. ${ }^{1}$ The analytical framework combines concepts from evolutionary economics (trajectories, regimes, niches, speciation, path dependence, routines), science and technology studies (sense making, social networks, innovation as a social process shaped by broader societal contexts), structuration theory and neo-institutional theory (rules and institutions as 'deep structures' on which knowledgeable actors draw in their actions, duality of structure, i.e. structures are both context and outcome of actions, 'rules of the game' that structure actions). These theoretical micro-assumptions have been articulated elsewhere (Geels, 2004; Geels and Schot, 2007, 2010).

The MLP views transitions as non-linear processes that results from the interplay of developments at three analytical levels: niches (the locus for radical innovations), socio-technical regimes (the locus of established practices and associated rules that stabilize existing systems), and an exogenous sociotechnical landscape (Rip and Kemp, 1998; Geels, 2002, 2005a). Each 'level' refers to a heterogeneous configuration of elements; 'higher' levels are more stable than 'lower' levels in terms of number of actors and degrees of alignment between the elements. While early work characterized the MLP as a nested hierarchy, Section "Flat ontologies versus hierarchical levels" proposes to drop that qualification. The regime level is of primary interest, because transitions are defined as shifts from one regime to another regime. The niche and landscape levels can be seen as 'derived concepts', because they are defined in relation to the regime, namely as practices or technologies that deviate substantially from

\footnotetext{
${ }^{1}$ Merton (1968) introduced the notion of middle range theory (MRT) to navigate between the extremes of grand theory (such as Parson's structural functionalism) and abstracted empiricism, which focuses only on data-collection and -analysis. Merton (1968:39) defined MRT as "theories that lie between the minor but necessary working hypotheses that evolve in abundance during day-to-day research and the all-inclusive systematic efforts to develop a unified theory that will explain all the observed uniformities of social behavior, social organization and social change". MRT has the following characteristics (Geels, 2007): (a) MRT are not about broad, abstract entities such as 'society' or 'social system', but about concrete phenomena (such as socio-technical transitions), (b) MRT differs from grand theory, because it emphasizes interactions between theory and empirical research. So, MRT do not consist of elaborate frameworks with endless conceptual distinctions and limited linkages to empirical research, (c) MRT specify relationships between concepts into analytical models: "An array of concepts does not constitute theory. (...) It is only when such concepts are interrelated in the form of a scheme that a theory begins to emerge" (Merton, 1968:143). The MLP is such a scheme that relates various concepts and uses empirical research to identify recurring patterns and generalizable lessons.
} 


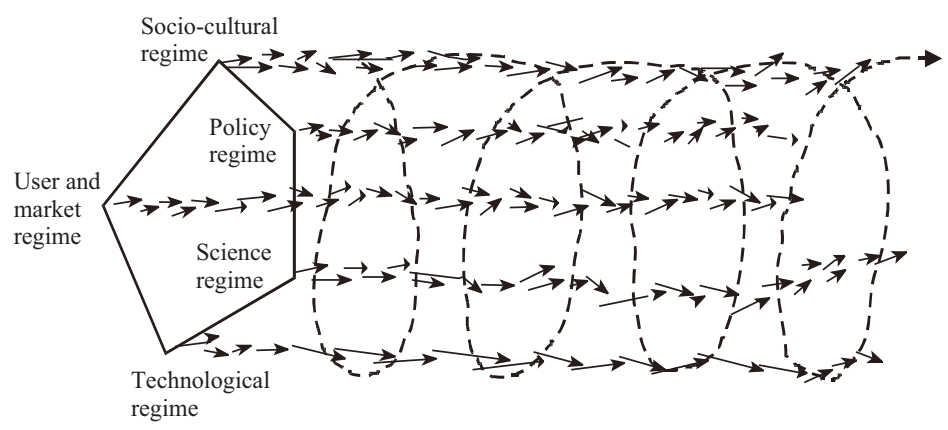

Adapted from Geels (2004:912).

Fig. 1. Alignment of ongoing processes in a socio-technical regime.

the existing regime, and as external environment that influences interactions between niche(s) and regime. $^{2}$

\subsection{Socio-technical regime}

The socio-technical regime forms the 'deep structure' that accounts for the stability of an existing socio-technical system (Geels, 2004). It refers to the semi-coherent set of rules that orient and coordinate the activities of the social groups that reproduce the various elements of socio-technical systems. Following Giddens (1984), these regime rules are both medium and outcome of action ("duality of structure"). On the one hand, actors enact, instantiate and draw upon rules in concrete actions in local practices; on the other hand, rules configure actors. Examples of regime rules are cognitive routines and shared beliefs, capabilities and competences, lifestyles and user practices, favourable institutional arrangements and regulations, and legally binding contracts. Because existing regimes are characterized by lock-in, innovation occurs incrementally, with small adjustments accumulating into stable trajectories. These trajectories occur not only in technology, but also in cultural, political, scientific, market and industrial dimensions. While science, technology, politics, markets, user preferences and cultural meanings have their own dynamics, coordinated by different sub-regimes, they also interpenetrate and co-evolve with each other (Fig. 1). The socio-technical regime concept aims to capture the meta-coordination between different sub-regimes (Geels, 2004). The alignment between sub-regimes can provide additional stability, but can also lead to tensions (see Section "Socio-technical landscape as residual category").

\subsection{Niches}

Niches are 'protected spaces' such as R\&D laboratories, subsidised demonstration projects, or small market niches where users have special demands and are willing to support emerging innovations. Niche actors (such as entrepreneurs, start-ups, spinoffs) work on radical innovations that deviate from existing regimes. Niche-actors hope that their promising novelties are eventually used in the regime or even replace it. This is not easy, however, because the existing regime is stabilized by many lock-in mechanisms and because niche-innovations may have a mis-match with existing regime dimensions (e.g. lack of appropriate infrastructure, regulations or consumer practices). Niches are crucial for transitions, because they provide the seeds for systemic change. The literature on nicheinnovation (Kemp et al., 1998; Schot and Geels, 2008) distinguishes three core processes in niche development:

2 I want to thank one of the reviewers for the suggestion of 'derived concepts'. 
Increasing structuration

of activities in local practices

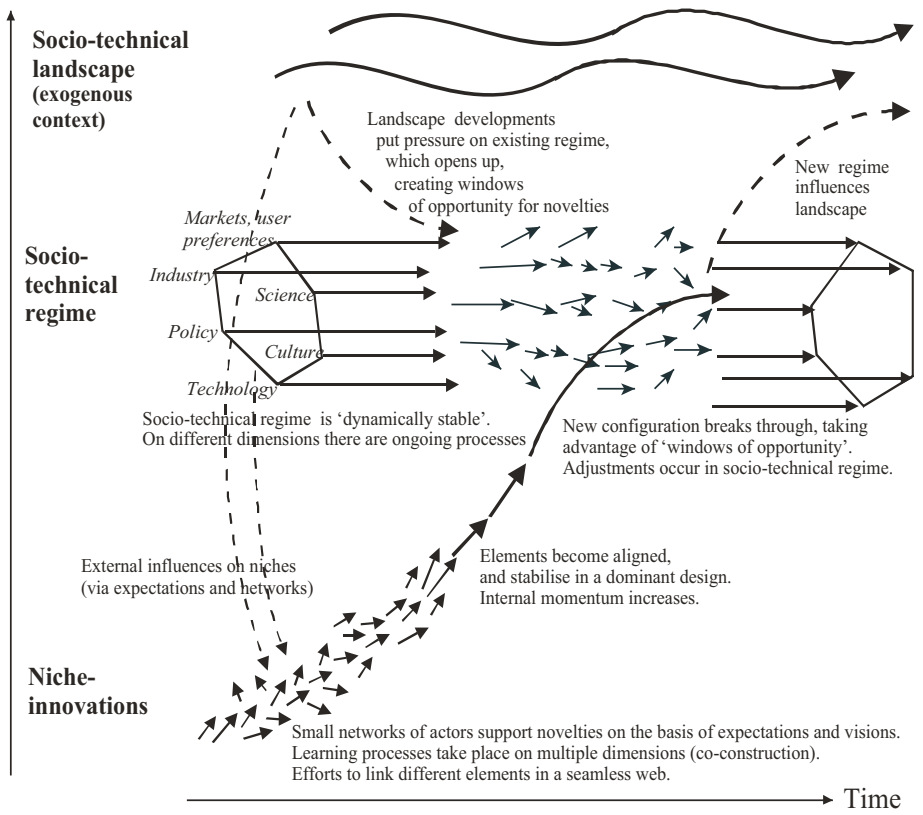

Adapted from Geels (2002:1263).

Fig. 2. Multi-level perspective on transitions.

- The articulation (and adjustment) of expectations or visions, which provide guidance to the innovation activities, and aim to attract attention and funding from external actors.

- The building of social networks and the enrolment of more actors, which expand the resource base of niche-innovations.

- Learning and articulation processes on various dimensions, e.g. technical design, market demand and user preferences, infrastructure requirements, organisational issues and business models, policy instruments, symbolic meanings.

Niches gain momentum if expectations become more precise and more broadly accepted, if the alignment of various learning processes results in a stable configuration ('dominant design'), and if networks become larger (especially the participation of powerful actors may convey legitimacy and resources to niche-innovations).

\subsection{Socio-technical landscape}

The sociotechnical landscape is the wider context, which influences niche and regime dynamics (Rip and Kemp, 1998). The landscape level, which has similarities to the concept of longue durée proposed by the historian Braudel, highlights not only the technical and material backdrop that sustains society, but also includes demographical trends, political ideologies, societal values, and macro-economic patterns. This varied set of factors can be combined within a single 'landscape' category, because they form an external context that actors at niche and regime levels cannot influence in the short run. The landscape level usually changes slowly (but see the discussion in Section "Flat ontologies versus hierarchical levels").

Fig. 2 provides an ideal-typical representation of how the three levels interact dynamically in the unfolding of socio-technical transitions. Although each transition is unique, the general dynamic 
pattern is characterized by transitions resulting from the interaction between processes at different levels: (a) niche-innovations build up internal momentum, (b) changes at the landscape level create pressure on the regime, and (c) destabilisation of the regime creates windows of opportunity for nicheinnovations. The unfolding interactions can be further sub-divided into several phases, e.g. emergence, take-off, acceleration and stabilization (Rotmans et al., 2001). Each of these phases can be linked to particular mechanisms (Geels, 2005a).

An important implication is that the MLP does away with simple causality in transitions. There is no single 'cause' or driver. Instead, there are processes in multiple dimensions and at different levels which link up with, and reinforce, each other ('circular causality').

The usefulness of the MLP has been illustrated with many historical case studies of transitions, such as in land transport (Geels, 2005a), shipping (Geels, 2002), cargo handling (Van Driel and Schot, 2005), as well as in sewers and sanitation, clean water (drinking, washing, bathing), aviation, highway systems, and industrial production. But the MLP has also fruitfully been applied in studies of contemporary and future transitions to sustainability, e.g. in electricity systems (Verbong and Geels, 2007, 2010; Hofman and Elzen, 2010), mobility and 'green' cars (Nykvist and Whitmarsh, 2008; Van Bree et al., 2010; Geels et al., 2011), biogas and co-combustion (Raven, 2004), organic food and sustainable housing (Smith, 2007), and animal welfare in pig farming (Elzen et al., 2011). Many of these contemporary studies explain the ups and downs of 'green' niche-innovations by analyzing the learning processes, network dynamics, and struggles against existing regimes on multiple dimensions.

\section{Criticisms, responses, and suggestions for future research}

The structure of the subsequent sections is that I describe the criticism, provide a response or qualification, and try to make productive suggestions for future research. Not all of the criticisms can be entirely resolved, because some of them relate to differences in assumptions or academic styles. In those instances, I aim to clarify the choices and styles that are related to the MLP.

\subsection{Lack of agency}

The MLP has been criticized for underplaying the role of agency in transitions. Smith et al. (2005) find it "too descriptive and structural, leaving room for greater analysis of agency" (p. 1492). Given their interest in the governance of socio-technical transitions, they especially argue for more attention for the role of power and politics. Genus and Coles (2008) repeat this point and suggest that the MLP should incorporate constructivist approaches, such as social construction of technology (SCOT), actornetwork theory (ANT) and constructive technology assessment (CTA), in order to "show concern for actors and alternative representations that could otherwise remain silent" (p. 1441).

Although stylized representations such as in Fig. 1 do not explicitly show actors, the MLP is shot through with agency, because the trajectories and multi-level alignments are always enacted by social groups. The $Y$-axis, which refers to 'increasing structuration of activities in local practices', indicates that the different structural levels are continuously reproduced and enacted by actors in concrete activities. ${ }^{3}$ Because trajectories in the MLP (represented as arrows) are enacted, the dynamics are similar to Garud and Karnøe's (Garud and Karnøe, 2001:3) view on path creation:

"By stressing path creation, we draw attention to phenomenona in the making, that is, the temporal processes that underlie the constitution of phenomena. Such a perspective assumes reciprocal interactions between economic, technical and institutional forces that constitute technological artefacts and actors involved. Thus, social orders, institutional orders and artifacts are both the medium and outcome of human endeavors".

\footnotetext{
${ }^{3}$ This has been further articulated in papers that specify the theoretical logic of the crossovers between evolutionary economics, STS, neo-institutional theory and structuration theory (Geels, 2004; Geels and Schot, 2007, 2010).
} 
Table 1

Three layers of power (Grin et al., 2010:283).

\begin{tabular}{|c|c|c|}
\hline Type of power & Focus & Level in MLP \\
\hline Relational & $\begin{array}{l}\text { Achievement of outcomes by agents in interaction, differences in } \\
\text { competencies and ability. }\end{array}$ & Experiments \\
\hline Dispositional & $\begin{array}{l}\text { Positioning of agents in a regime, comprising rules, resources, } \\
\text { actor configurations and dominant images of the issue involved. }\end{array}$ & Regime \\
\hline Structural & $\begin{array}{l}\text { Structuring of arrangements, from changing orders of signification, } \\
\text { domination and legitimisation (Giddens). }\end{array}$ & Slowly changing landscape \\
\hline
\end{tabular}

So, MLP proponents feel that agency has always been present in the MLP. ${ }^{4}$ Because the MLP is based on crossovers between evolutionary economics and STS (constructivism), it aims to bridge the social science divide between 'materialist' and 'idealist' theories. ${ }^{5}$ From evolutionary economics it includes materialist aspects (such as prices, capital stocks, investments, resources, competition, market selection, struggle for survival) and from STS it includes idealist aspects (such as interpretations, visions, beliefs, networks, framing struggles, debate). So, the MLP accommodates agency in the form of bounded rationality (routines, search activities, trial-and-error learning) and interpretive activities. It is therefore incorrect to claim that the MLP does not accommodate agency. But it is probably fair to say that certain types of agency are less developed, e.g. rational choice, power struggles, culturaldiscursive activities (Geels, 2010). While detailed case studies show some of these types of agency, the MLP can be theoretically enriched by mobilizing insights from other theories. This enrichment could also improve the understanding of the mechanisms through which various dimensions (technical, market, cultural, political, etc.) and various levels interact. Because the MLP is a middle range theory, it could benefit from including insights from auxiliary theories. I discuss three examples.

Grin et al. (2010) draw on political science theories to develop the role of power in the MLP. He proposes that different types of power characterize the various levels (Table 1 ). While power has different sources, it also needs to be enacted, which depends on skills (e.g. bargaining, making threats or backroom deals).

Elzen et al. (2011) incorporate insights from social movement theory into the MLP to understand how external normative concerns can influence existing regimes. They show that social movements engage in resource mobilization, framing activities, and nurturing of technical alternatives. Drawing on Kingdon's multiple streams model, they also show that the effectiveness of social movement activities depends on political opportunity structures and alignments of normative pressures with market and technology developments.

Geels and Verhees (2011) develop the cultural dimension in the MLP by drawing on cultural sociology, discourse theory and social movement theory. They show that discursive activities at regime and niche levels draw on cultural repertoires at the landscape level. They further show that opponents and proponents adjust their discursive framings to increase the salience of discourses on five dimensions (actor credibility, empirical fit, centrality, experiential commensurability, macro-cultural resonance).

So, there are attempts to further develop the MLP and include other types of agency. Attempts that relate to power, civil society and cultural dimensions are important to better understand agency that relates to the first two special characteristics of sustainability transitions, discussed in the introduction (debates about directionality and desirable solutions; power struggles over adjustments in economic frame conditions). To address the third special characteristics (the continuing importance of regime actors), the MLP could benefit from stronger incorporation of insights from business studies and strategic management. The literature on strategic alliances can offer relevant insights in collaborations between incumbents and new entrants in the development of niche-innovations (Rothaermel,

\footnotetext{
${ }^{4}$ The suggestion by Genus and Coles to incorporate SCOT and CTA is somewhat strange, since these approaches were an input to the MLP from the start. The suggestion to incorporate ANT creates theoretical inconsistencies, because ANT's ontological assumptions (a flat ontology) differ from the MLP (Geels, 2010) (see also Section "Flat ontologies versus hierarchical levels").

5 'Materialist' scholars (e.g. Marx) tend to focus on objective, measurable, and quantifiable variables, often of a technoeconomic nature. 'Idealist' thinkers (going back to Plato) focus on the ideas and beliefs that people have, which are more intangible, subjective, and cultural-interpretive.
} 
2001). And the literatures on ambidextrous organizations (Tushman and O'Reilly, 1996) and on strategic tensions between the exploitation of existing technologies and the exploration of new ones (March, 1991) can offer relevant insights regarding the strategic reorientation of regime actors towards nicheinnovations.

\subsection{Operationalization and specification of regimes}

Several criticisms concern the operationalization and specification of regimes. Berkhout, Smith, and Stirling (Berkhout et al., 2004:54) claim that "it is unclear how these conceptual levels should be applied empirically. By this we mean that a sociotechnical regime could be defined at one of several empirical levels". In the electricity domain one could study a regime at the level of primary fuel (coal, oil, gas) or at the level of the entire system (production, distribution and consumption of electricity). What looks like a regime shift at one level may be viewed merely as an incremental change in inputs for a wider regime at another level.

This criticism is about the normal problem of drawing boundaries and defining the topic of analysis. The MLP does not prescribe how broad or narrow the empirical topic should be delineated. The regime notion is an analytical concept that can be applied to empirical topics of different scope (primary fuels or entire electricity systems). The scope of the empirical topic will have implications for the operationalization of the regime concept (e.g. the number of actors, their relationships and the coordinating rules/institutions). So, the analyst should first demarcate her object of analysis and then operationalise the analytical levels from the MLP.

Genus and Coles (2008) call for more operationalisation, specification and delineation of the MLP and the regime concept in particular. Markard and Truffer (2008) also criticise the regime-concept which sometimes refers to 'rules', and at other times is used as a shorthand for 'system'. They therefore find the conceptual differentiation between system and regime "not convincing" (p. 605) and call for greater "conceptual rigor in the identification and delineation of a regime" (p. 606).

I agree with the critics that empirical studies sometimes use 'regime' as shorthand for 'system'. Additionally, there is sometimes a tendency to reify the regime and attribute intentionality and strategy to it, which seems to grant regimes a life of their own. The reason is probably that these empirical studies tend to be interested more in the macro-patterns of transitions than in the micro-sociological dynamics (with knowledgeable actors drawing on regime rules when reproducing, maintaining or altering system elements). The theoretical papers, however, tend to be more precise about the analytical difference between 'regime' and 'system' (Geels, 2004; Geels and Schot, 2007, 2010). System then refers to tangible and measurable elements (such as artefacts, market shares, infrastructure, regulations, consumption patterns, public opinion), whereas regimes refer to intangible and underlying deep structures (such as engineering beliefs, heuristics, rules of thumb, routines, standardized ways of doing things, policy paradigms, visions, promises, social expectations and norms). So 'regime' is an interpretive analytical concept that invites the analyst to investigate what lies underneath the activities of actors who reproduce system elements.

Another criticism is that socio-technical regimes are often presented as too homogeneous or monolithic (Smith et al., 2005). That is probably true, especially for studies that focus on niche-innovations and how they struggle against existing regimes. Still, regimes have been defined as semi-coherent rulesets (Rip and Kemp, 1998; Geels, 2004), which allow for the possibility of tensions between rules from different sub-regimes (see also Fig. 1). While regimes may appear as coherent blocks from the outside (and often present themselves that way through spokespersons such as trade associations), there are often internal tensions, disagreement and conflicts of interests. Neo-institutional theorists (Hoffman, 1999; Seo and Creed, 2002) have made the same point, arguing that organizational fields are full of debates on specific issues and problems. So, it may be better to say that, on the one hand, regimes have coherence, shared rules, and similarity, but on the other hand contain variety, disagreement on specific issue, debate, and internal conflict. Such a conceptualization would make the strength, homogeneity and internal alignment of regimes an empirical question rather than an assumption.

A criticism with regard to transition processes is that most work seems to focus on a single regime, which faces pressures from niche-innovations and landscape developments. This also applies to the typology of transition pathways, discussed in Section "Bias towards bottom-up change models". But for 
sustainability transitions, it may be fruitful to pay more attention to multi-regime interactions (Raven, 2007; Konrad et al., 2008). The growth of certain niche-innovations by definition requires interactions between two (or more) regimes: co-generation of heat and power links heat and electricity regimes, biofuels link agriculture and transport regimes, battery-electric vehicles link transport and electricity systems. Positive and negative influences from other regimes on the focal regime are an understudied but promising topic.

\subsection{Bias towards bottom-up change models}

The MLP has been criticized for a bias towards bottom-up change models. Berkhout et al. (2004:62) suggest that MLP-approaches "tend unduly to emphasize processes of regime change which begin within niches and work up, at the expense of those which directly address the various dimensions of the sociotechnical regime or those which operate 'downwards' from general features of the sociotechnical landscape".

I agree that some early work emphasized bottom-up dynamics where radical innovations emerge in technological niches, then enter small market niches and subsequently diffuse into mainstream markets and replace existing regimes. Geels (2002:1261) therefore emphasized the importance of alignments with broader developments are equally important for transitions: "To counter this bias, I think more explicit attention needs to be paid to ongoing processes at the regime and landscape level". Nevertheless, many studies of sustainability transitions focus primarily on 'green' niche-innovations (and then frame regimes as 'barriers to be overcome'). To overcome the bottom-up niche bias, Geels and Schot (2007) differentiated the MLP by varying the timing of multi-level interactions and the nature of multi-level interactions (competitive or symbiotic). This resulted in four transition pathways:

- Transformation: In this pathway, landscape developments exert pressure on the regime when nicheinnovations are not well-developed. Incumbent actors modify the direction of innovation activities and development paths, which leads to gradual adjustments of regimes to landscape pressures. Although niche-innovations do not break through in this path, experiences from niches can be translated and accomodated (often in a watered-down form) in the regime (Smith, 2007).

- Reconfiguration: In this pathway, niche-innovations are more developed when landscape developments exert pressure on regimes. If niches are symbiotic to the regime, incumbent actors can adopt them as 'add-ons' to solve local problems. This incorporation can trigger subsequent adjustments, which change the regime's basic architecture.

- Technological substitution: In this pathway, competitive niche-innovations are well developed when landscape developments exert pressure on regimes. Tensions in the regime form a window of opportunity for the break through of niche-innovations that replace the regime. An alternative route is that niche-innovations gain high internal momentum (because of resource investments, consumer demand, cultural enthusiasm, political support, etc.), in which case they can replace the regime without the help of landscape pressures.

- De-alignment and re-alignment: In this pathway, major landscape pressures first cause disintegration of regimes (de-alignment). Then, taking advantage of this 'space', multiple niche-innovations emerge, which co-exist for extended periods (creating uncertainty about which one will become the winner). Processes of re-alignment eventually occur around one innovation, leading to a new regime.

The basic point of this typology is the articulation of change models that go beyond the bottomup bias. Similar debates about bottom-up and other change models can be found in the literature on political revolutions, which may therefore offer inspiration for the study of sustainability transitions. Sztompka (1993), for instance, distinguishes four types of change models, which focus either on (bottom-up) agency or structural conditions.

(1a) The 'volcanic' model suggests that revolutions spontaneously break out from below. When tensions, grievances, and discontents pass a certain threshold, the masses rise up and overthrow the incumbent elites. Whereas the traditional colcanic model emphasized objective conditions of hardship, Goldstone's fourth generation of revolutionary theory (Goldstone, 2001) highlights the 
importance of ideology and cultural framing in making people become aware of their conditions and in constructing feelings that existing socio-economic or political conditions are unacceptable.

(1b) In the 'conspirational' (or leadership) model, agency comes from outside agitators, professional revolutionary vanguards (Lenin) or sidelined elite groupings. These actors push the masses to revolutionary action (and sometimes manipulate them to further their own goals). In this perspective, revolutions do not break out but result from a plot or are guided by experts. ${ }^{6}$

(2a) The 'safety-lid' model argues that revolutionary uprisings are frequent, but usually do not succeed because of repression by existing elites. Revolutions must therefore be preceded by the destabilization of existing elite coalitions such as a breakdown of governmental control or a relaxation of repressive measures. Skocpol's famous model (Skocpol, 1979) suggests that rural uprisings can only be successful if the coalition between the state and the landed classes has weakened. In particular, she emphasizes the role of external shocks, such as international conflict that forces the state to increase military expenditures and raise taxes, which creates tensions with the landed classes. In those circumstances rural uprisings can lead to revolutions. She empirically demonstrates her model for revolutions in France, China and Russia.

(2b) The 'structural opportunity' model suggests that broader secular changes create favorable conditions for revolutionary uprisings. Urbanization, for instance, facilitates mobilization, because it creates proximity of large masses of people. Or rapid social change can produce social disorganization and imbalance that facilitates revolutionary mobilization.

This typology shows that bottom-up dynamics form only one type of large-scale change. While political revolutions are not entirely similar to socio-technical transitions, we can probably learn from these broader kinds of change models. Dahle (2007) made an interesting attempt to draw lessons for sustainability transitions. He distinguishes four strategic profiles, which have some similarities to the transition pathways and revolutionary change models:

(1) Reformists: Existing elites (in politics and business) gradually change existing institutions in greener directions (e.g. through green taxes and international environmental treaties). This profile has similarities to the transformation pathway in which the regime adjusts to external pressures.

(2) Impatient revolutionaries: The existing elite should be replaced (overthrown) by a new elite of environmental experts, who are willing to implement drastic measures. Democratic consent is not crucial, because "there is no time to wait for the majority of the population to agree on the necessary changes" (Dahle, 2007:492). This profile has similarities to the conspirational/leadership model $^{7}$ and the substitution transition path.

(3) Grassroots fighters: Change must spring from below, outside the existing institutions. Social movements should develop alternative structures (cooperatives, communes, ecovillages) and hope that the majority will be influenced by the power of the example. This profile has similarities to the volcanic model and the substitution transition path.

(4) Patient revolutionaries: Green initiatives have little chance until existing structures open up or collapse, which may require environmental shocks or disasters. Until this happens, patient revolutionaries should nurture niche-innovations and prepare for the right moment by facilitating learning processes, public education and awareness raising. This profile has similarities to the safety-lid model, the structural opportunity model, and the de-alignment and re-alignment pathway.

The above discussions show that broader change models form fruitful terrain for future research on large-scale transitions, which goes beyond an exclusive bottom-up bias.

\footnotetext{
${ }^{6}$ The transition management model (Rotmans et al., 2001) has elements of this model, because of its emphasis on visionary leadership and frontrunners.

7 The transition management approach (Rotmans et al., 2001) has also been criticized for a democratic disconnect (Hendriks, 2008).
} 


\subsection{Heuristics, epistemology and explanatory style}

With regard to epistemological status Genus and Coles (2008) suggest that the "potential contribution of the MLP/transitions framework could be limited to offering a heuristic device" (p. 1442).

While this qualification may be a severe criticism in positivist research traditions, heuristics are seen as important in interpretive traditions. I therefore take the qualification as a compliment in the sense that MLP frames the topic of transitions in a certain way and asks particular questions about patterns and mechanisms. I offer three further responses with regard to explanatory and theoretical styles.

The first is that open frameworks may be more suited to investigate the co-evolutionary dynamics of transitions than precise models. Defending his work on broad approaches to corporate strategy, Porter (1991) made a similar point, when he distinguished two approaches to theory building. The first approach refers to "rigorous (often mathematical) models of limited complexity, which (...) isolates a few key variables whose interactions are examined in depth" (Porter, 1991:97). While such rigorous models are possible for demarcated topics, they may be less useful for broader, multi-dimensional topics. For those topics, the second approach, heuristic perspectives, appear more relevant. These "frameworks identify the relevant variables and the questions which the user must answer to order to develop conclusions tailored to a particular industry and company. (...) In addition, all the interactions among the variables in the frameworks cannot be rigorously drawn. The frameworks, however, seek to help the analyst to better think through the problem" (Porter, 1991:98).

Frameworks such as the MLP are not 'truth machines' that automatically produce the right answers once the analyst has entered the data. Instead they are 'heuristic devices' that guide the analyst's attention to relevant questions and problems. Their appropriate application requires both substantive knowledge of the empirical domain and theoretical sensitivity (and interpretive creativity) that help the analyst 'see' interesting patterns and mechanisms.

The second response is that the MLP is more a middle-range theory than a grand theory. Although STS (constructivism) and evolutionary economics form the MLP's theoretical underpinnings, there is scope for scholars to conceptualize dynamic mechanisms with auxiliary theories. This is possible because evolutionary theory can be used as an open framework that accommodates both economic and sociological understandings:

"Darwinism provides an over-arching framework of explanation, but without claiming to explain every aspect or detail. (...) the transfer of Darwinian principles from biological to social evolution does not imply that the detailed mechanisms of selection, variation and inheritance are similar" (Hodgson and Knudsen, 2004:15).

"Darwinism does not itself provide all the necessary causal mechanisms and explanations for the social scientist, nor obviate the elaborate additional work of specific investigation and detailed causal explanation in the social sphere. (...) It is more a meta-theoretical framework than a complete theory" (Hodgson and Knudsen, 2004:17).

The third response is that the MLP employs 'process theory' as explanatory style rather than 'variance theory' (Geels and Schot, 2010). Process theories do not explain variance in the dependent variable as 'caused' by independent variables, but instead explain outcomes in terms of event sequences and the timing and conjunctures of event-chains (Pettigrew, 1997; Abbott, 2001; Langley, 2007). Depending on the research topic and question, these can be micro-events such as moves and counter-moves by actors, or they can be macro-events as in Fig. 3, which interprets the English industrial revolution as the outcome of three event sequences: an environmental sequence, a cultural sequence and an industrialization sequence. ${ }^{8}$

To explain outcomes, the analyst thus needs to trace unfolding processes and study event sequences, timing, and conjunctures. Process-oriented scholars have therefore turned towards narrative explanation (Abell, 2004; Pentland, 1999) because narratives can capture complex interactions

\footnotetext{
${ }^{8}$ I include this representation to illustrate the logic of event chains and conjunctures, not to give an in-depth historical account of the Industrial Revolution.
} 


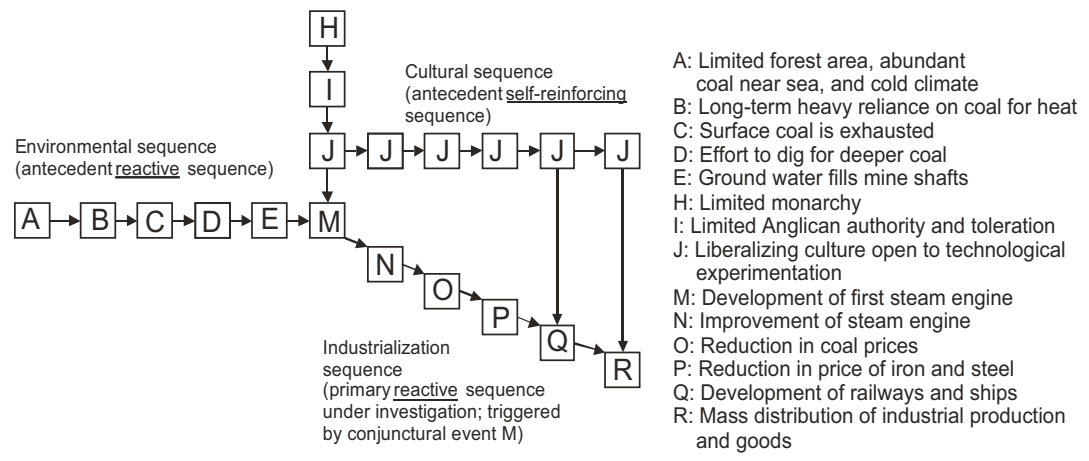

Fig. 3. Conjunctural sequence explanation of English industrialization (Mahoney, 2000:534).

between agency and changing contexts, time, event sequences, making moves in games, and changing identities. Abbott (1991:227) elaborates that:

"Theorizing the social process via narrative is a deep tradition in both history and sociology. If there is any one idea central to historical ways of thinking, it is that the order of things makes a difference, that reality occurs not as time-bounded snapshots within which "causes" affect one another (...), but as stories, cascades of events."

Not all narratives can be seen as process theories, however. Some narratives only describe "one damn thing after another." To develop causal narratives, explanations therefore need be guided by 'heuristic devices' such as conceptual frameworks that specify a certain plot:

"Narratives are not just sequences of events, but are tied together by a central theme. I argue that the contextual framework can serve as a theoretical/explanatory theme that endures throughout the analysis in ways that discipline the narrative" (Pedriana, 2005:357).

The multi-level perspective provides such a plot for the study of transitions. Still, causal narratives of specific transitions need to trace event sequences and the conjunctures within and between levels. With regard to Skocpol's famous work on socio-political revolutions, Sewell (1996) makes a similar point, arguing that the plausibility of her framework derives not only from theoretical logic, but also from "carefully constructed causal narratives specifying how social revolutions are brought about in her three cases" (p. 260). "In fact, all three revolutions can be narrated convincingly in terms of the operation of analogous causal processes. (...) The 'proof' is less in the formal logic than in the successful narrative ordering of circumstantial detail" (p. 262). Although the specific event sequences of each revolution (or transition) are different, process theories such as Skocpol's framework or the MLP can claim versatility or generality when they are able to identify recurring causal patterns.

While the MLP provides a useful overall plot ('global model') for studying transitions, transition scholars have distinguished specific patterns that are played out in shorter time periods. Some examples from my work are hype-disappointment cycles, niche-accumulation pattern, fit-stretch pattern, knock-on effects and innovation cascades, add-on and hybridization pattern (Geels, 2005b). ${ }^{9}$ Future

\footnotetext{
9 'Hype-disappointment cycles' refer to the pattern that early beliefs and hopes of new technologies are often too high (partly because of promises from product-champions), which leads to disappointments when problems appear or technical progress is slower than expected. 'Niche-accumulation' refers to the pattern that new technologies diffuse into markets through a sequence of application domains. 'Fit-stretch' refers to the pattern that new technologies are initially interpreted in categories that are close to the existing regime (fit). Subsequent learning processes may gradually lead to new ideas about technical form and social function ('stretch'). 'Knock-on effects' and 'innovation cascades' mean that new technologies may be adopted in a system for certain reasons. But learning processes and improvements may then trigger further adjustments in other system components (both technical and non-technical). 'Add-on' and 'hybridization' refer to the pattern that old and new technologies may have symbiotic relations, with new technologies initially fulfilling only auxiliary functions, but gradually becoming more important leading to hybrid configurations.
} 
research could aim to identify more recurring patterns. The focus on patterns and mechanisms may enable transitions research to articulate an epistemological middle way between on the one hand the search for laws and statistical correlations between variables (as in mainstream social science), and on the other hand an emphasis on complexity, contingency, fluidity, untidiness and ambiguity (as in constructivist micro-studies).

\subsection{Methodology}

With regard to the historical case studies that illustrate the MLP, Genus and Coles (2008) criticise the "flawed use of secondary data sources", especially the use of "uncritically 'accepted' accounts of the historical significance of certain socio-technical developments" (p. 1441).

I recognize that the methodological discussion in my case studies is underdeveloped with regard to discussing the quality of data sources. So, it could be that I reproduced incorrect interpretations in the secondary literature. But the criticism remains under-specified, because Genus and Coles do not indicate which empirical mistakes were made in particular case studies. Furthermore, their claim is overstated because they do not discuss other MLP-related work that is based on primary data sources (Van Driel and Schot, 2005; Raven, 2004; Smith, 2007). Still, it is probably fair to say that, so far, transition case studies aimed more at illustration and exploration than at systematic research.

There are deeper problems, however, for process theories of multi-facetted topics. Because process theories tend to emphasise complex dynamics such as path dependence, interaction effects, tipping points, thresholds, bifurcations, and conjunctures, they may be at odds with assumptions required for standard regression techniques and conventional comparative methods. Hall (2003:387) therefore suggests that "our ontologies have outrun both our methodologies and standard views of explanation". Abell (2004) makes a similarly point when he argues that: "Narrative explanation derives from an ontological primacy, while variable-centered explanation has epistemological primacy" (p. 306). This comment points to a broader trade-off. Mainstream social science tends to emphasize method (e.g. rigorous procedures for data gathering, data analysis, replication), but has a relatively simple ontology. Process theories, in contrast, tend to have a more complex ontology, but less developed methodology.

This general dilemma also affects the MLP, with most empirical research using (single) case study methodologies. So, transition research could probably benefit from the application of other methods such as comparative or nested case studies, event-sequence analysis, network analysis, even-history methods, and agent-based modelling. My concern, however, is that the MLP should not be reduced to a mechanical procedure by forcing it into a variance theory straightjacket. The research of complex phenomena such as transitions cannot be reduced to the application of methodological procedures and will always contain elements of creative interpretation.

\subsection{Socio-technical landscape as residual category}

The landscape level has been criticized for being a residual analytical category, a kind of 'garbage can' concept that accounts for many kinds of contextual influences. This is a fair criticism, which can be made productive by reformulating it as a need for more theorization. Some suggestions are the following.

First, the landscape concept can be made more dynamic. Early publications characterized the sociotechnical landscape as stable or very slow moving, like soil conditions, lakes and mountain ranges in biological evolution. Van Driel and Schot (2005) developed a more differentiated view with three types of landscape dynamics: (1) factors that do not change (or that change very slowly), such as physical climate, (2) rapid external shocks, such as wars or oil price fluctuations, and (3) long-term changes in a certain direction (trend-like patterns), such as demographical changes.

Second, more attention could be paid to landscape developments that help stabilize existing regimes. Studies of sustainability transitions often highlight landscape trends that (could) exert destabilizing influences on regimes, e.g. climate change or Peak Oil. But balanced assessments of (chances for) transitions should also address stabilizing landscape developments. Car-based mobility systems, for instance, are stabilized by landscape trends such as (Geels et al., 2011): (a) globalization and increasing world-trade, (b) individualization and people becoming more footloose, (c) rapidly growing interna- 
tional tourism, (d) growing wealth and the rise of second and third cars in households, and (e) a shift towards a network society that generates increasing flows and 'space of flows' that facilitate them. A subsequent puzzle then becomes how to determine the relative influence of stabilizing and destabilizing landscape developments.

Third, scholars could investigate the reverse causality and ask how regime shifts contribute to landscape changes. An interesting option for theoretical work is to link the MLP to work on long-waves (Perez, 2002): economy-wide techno-economic paradigm shifts could perhaps be conceptualized as arising from multiple regime shifts. Along similar lines, Berkhout et al. (2009:225) suggest that macroeconomic development can be studied as the outcome of "the emergence of new socio-technical systems, replacing or radically altering traditional and early modern systems in key sectors, including energy, transport, agriculture and food, water and urban development". They suggest that "the systems innovation framework appears to offer a new way of viewing processes of economic development that focuses on formation and reconfiguration of socio-technical regimes" (p. 226). This suggestion, which entails an ambitious attempt to link transition studies with broader economic development debates, remains to be further developed.

\subsection{Flat ontologies versus hierarchical levels}

From a relationist ontology, which assumes a 'flat' world, the idea of 'levels' can be criticized.

“So you are freed from this image of a multilevel society. You don't need several layers, different layers. (...)You only need places that are connected and the possibility of actors and information to circulate from one place to another one." (Callon, 2002:293).

Shove and Walker (2010:474) specifically propose replacing the MLP with social practice theory, which emphasises "the horizontal circulation of elements and argues for a flatter model characterized by multiple relations (rather than hierarchical levels) of reproduction across different scales". Social practices in daily life are seen as the outcome of actors who combine and reproduce different elements (technology, meaning, skills), which themselves circulate between practices. Their practice approach "underlines the extent to which systems of practice are subject to continual, ongoing reproduction. This is again in contrast to the more hierarchical aspect of the multi-level perspective" (p. 472). To explain transitions, practice theory distinguishes between: (a) more "enduring and relatively stable practices" (p. 475), which are routinely reproduced and characterized by predictable trajectories, and (b) new practices, which are more fluid and unstable. Transitions can be studied by analysing how new practices come into being, how they stabilize, and how established practices disappear.

Because flat ontologies have different foundational assumptions than the MLP, they, of course, conceptualize transitions differently. Still, there are similarities in the kinds of phenomena of interest and one could reformulate practice theory in MLP-terms (and probably the reverse as well): stable/routinized practices can be seen 'regimes', whereas emerging fluid practices can be seen as 'niche'. With regard to 'landscape', there is some disagreement in practice theory. Shove and Walker (2010:475) suggest that external landscape contexts do not exist: "it is misleading to imagine or suppose the existence of sources or forces of influence that are somehow external to the reproduction and transformation of practice". Røpke (2009:2493), however, argues for a pragmatic inclusion of broader contexts: "Social patterns such as the division of labour, gender relations, and unequal access to resources, as well as political, economic, legal and cultural institutions are constituted by practices, but they also provide a context for the performance of practices that is necessary to include in empirical analyses."

Maybe the bone of contention is less about levels per se than it is about the suggestion of hierarchy. If so, the critics may have a point. Although people often summarise the MLP as 'micro-meso-macro', the levels are defined as referring to different degrees of structuration of local practices, which relate to differences in scale and the number of actors that reproduce regimes (and niches). Levels thus refer to different degrees of stability, which are not necessarily hierarchical. This is a deviation from earlier MLP-work, which used the notion of 'nested hierarchy'. While this is an attractive metaphor, most niches do not emerge within regimes, but often outside them (although niche actors are usually aware 
of regime structures). While the socio-technical landscape is an external context, the relation with regimes (and niches) is not necessarily hierarchical (just as one would not characterize soil conditions, mountain ranges and rainfall patterns as hierarchical structures for biological evolution). So, perhaps we should consider dropping the 'hierarchy' notion in the MLP.

In sum, flat approaches seem an interesting and potentially fruitful alternative to the MLP. But because the ontology is (even more) complex than the MLP, there may be trade-offs with regard to accuracy, generalization, and empirical operationalization. Shove (2003) qualified her practice approach as "a different way of thinking" rather than as an "all-encompassing theoretical model" (p. 20). Because the practice concepts are more descriptive than explanatory, it remains somewhat unclear how they can be used to analyse transition dynamics in a way that goes beyond the empirical mapping of individual cases. At present, the MLP is therefore perhaps somewhat more developed in terms of specifying relevant mechanisms in transitions and identifying recurrent patterns. This could be due to the stage of development or to differences in epistemology and explanatory styles (see Section "Heuristics, epistemology and explanatory style"), with the MLP perhaps aiming to generalize via recurrent patterns and mechanisms, and practice theories (and flat approaches more generally) emphasising heterogeneity, contingency, fluidity, emergence, unpredictability, and untidiness.

\section{Concluding comments}

Socio-technical transitions (to sustainability) are a special research topic, because they are about relatively rare, long-term macro-changes. Since they do not frequently occur, it is difficult to construct large databases that can be analysed statistically for relationships between variables. Other types of theories and methodologies are therefore needed. These theories should be multi-dimensional, because it is unlikely that only one kind of causal factor or mechanism can explain entire transition processes.

Since transitions are a complex and multi-faceted research topic, researchers are likely to disagree about how best to investigate them. Recognizing that scholars still debate the origins and causes of the Industrial Revolution and the French revolution, it seems unlikely that differences in the sustainability transitions community will be resolved any time soon.

In response to criticisms, this paper has tried to clarify the choices and styles that underlie the multilevel perspective on socio-technical transitions. Because different styles have particular strengths and weaknesses, these choices entail trade-offs. So, there is not one right way to investigate socio-technical transitions. Still, I have tried to argue that the MLP is well suited to address the special characteristics of the transitions topic. Not everyone will agree with this claim, because scholars differ in their ontological assumptions, epistemological styles or methodological commitments. Disagreements may lead to critical debates which are the lifeblood of academic practice and may lead to refinement of theories and frameworks. Although criticism is important, an awareness of different styles may deepen the academic debate and prevent a style in which apples criticise oranges for not being apples.

Contrary to some of the critics, I prefer an academic style in which criticism is not only deconstructive (showing the problems, tensions, or shortcomings in a particular approach), but also constructive (extending the approach to remedy certain problems or providing an alternative approach). This paper therefore tried to translate some of the criticisms into productive suggestions for future research, which could take the MLP into new directions. While the research on socio-technical transitions and sustainability has made much progress in the last ten years, this research agenda suggests that much exciting research can still be done in the next ten years.

\section{Acknowledgements}

This work has been supported by an ERC grant (No. 204246). I want to thank Florian Kern, Inge Røpke, Ulrik Jørgensen, two anonymous reviewers, and the journal editors for their suggestions and comments on a previous version. 


\section{References}

Abbott, A., 1991. History and sociology: the lost synthesis. Social Science History 15, 201-238.

Abbott, A., 2001. Time Matters: On Theory and Method. University of Chicago Press, Chicago, IL.

Abell, P., 2004. Narrative explanation: an alternative to variance-centered explanation? Annual Review of Sociology 30, 287-310.

Anderson, P., Tushman, M., 1990. Technological discontinuities and dominant designs: a cyclical model of technological change. Administrative Science Quarterly 35, 604-633.

Berkhout, F., Smith, A., Stirling, A., 2004. Socio-technological regimes and transition contexts. In: Elzen, B., Geels, F.W., Green, K. (Eds.), System Innovation and the Transition to Sustainability: Theory, Evidence and Policy. Edward Elgar, Cheltenham, pp. 48-75.

Berkhout, F., Angel, D., Wieczorek, A.J., 2009. Asian development pathways and sustainable socio-technical regimes. Technological Forecasting \& Social Change 76, 218-228.

Callon, M., 2002. Technology, politics and the market: an interview with Michel Callon, conducted by Andrew Barry and Don Slater. Economy and Society 31, 285-306.

Christensen, C., 1997. The Innovator's Dilemma: When New Technologies Cause Great Firms to Fail. Harvard Business School Press, Boston, MA.

Dahle, K., 2007. When do transformative initiatives really transform? A typology of different paths for transition to a sustainable society. Futures 39, 487-504.

Elzen, B., Geels, F.W., Green, K. (Eds.), 2004. System Innovation and the Transition to Sustainability: Theory, Evidence and Policy. Edward Elgar, Cheltenham.

Elzen, B., Geels, F.W., Leeuwis, C.S., Van Mierlo, B., 2011. Normative contestation in transitions 'in the making': animal welfare concerns and system innovation in pig husbandry (1970-2008). Research Policy 40, 263-275.

Freeman, C., Louçă, F., 2001. As Time Goes By: From the Industrial Revolutions to the Information Revolution. Oxford University Press, Oxford.

Freeman, C., Perez, C., 1988. Structural crisis of adjustment, business cycles and investment behaviour. In: Dosi, G., Freeman, C., Nelson, R., Silverberg, G., Soete, L. (Eds.), Technical Change and Economic Theory. Pinter, London, pp. 38-66.

Garud, R., Karnøe, P. (Eds.), 2001. Path Dependence and Creation. Lawrence Earlbaum Associates, Mahwah, NJ.

Geels, F.W., 2002. Technological transitions as evolutionary reconfiguration processes: a multi-level perspective and a casestudy. Research Policy 31,1257-1274.

Geels, F.W., 2004. From sectoral systems of innovation to socio-technical systems: insights about dynamics and change from sociology and institutional theory. Research Policy 33, 897-920.

Geels, F.W., 2005a. The dynamics of transitions in socio-technical systems: a multi-level analysis of the transition pathway from horse-drawn carriages to automobiles (1860-1930). Technology Analysis \& Strategic Management 17, 445-476.

Geels, F.W., 2005b. Processes and patterns in transitions and system innovations: refining the co-evolutionary multi-level perspective. Technological Forecasting \& Social Change 72, 681-696.

Geels, F.W., 2007. Feelings of discontent and the promise of middle range theory for STS: examples from technology dynamics. Science, Technology \& Human Values 32, 627-651.

Geels, F.W., 2010. Ontologies, socio-technical transitions (to sustainability), and the multi-level perspective. Research Policy 39, 495-510.

Geels, F.W., Schot, J.W., 2007. Typology of sociotechnical transition pathways. Research Policy 36, 399-417.

Geels, F.W., Schot, J.W., 2010. The dynamics of transitions: a socio-technical perspective. In: Grin, J., Rotmans, J., Schot, J., Geels, F.W., Loorbach, D. (Eds.), Transitions to Sustainable Development: New Directions in the Study of Long Term Transformative Change. Routledge, New York, pp. 9-87.

Geels, F.W, Verhees, B., 2011. Cultural legitimacy and framing struggles in innovation journeys: a cultural-performative perspective and a case study of Dutch nuclear energy (1945-1986). Technological Forecasting and Social Change 78.

Geels, F.W., Kemp, R., Dudley, G., LyonsF G. (Eds.), 2011. Automobility in Transition? A Socio-Technical Analysis of Sustainable Transport. Routledge, New York.

Genus, A., Coles, A.-M., 2008. Rethinking the multi-level perspective of technological transitions. Research Policy 37, $1436-1445$. Giddens, A., 1984. The Constitution of Society: Outline of the Theory of Structuration. University of California Press, Berkeley.

Goldstone, J.A., 2001. Toward a fourth generation of revolutionary theory. Annual Review of Political Science 4, 139-187.

Grin, J., Rotmans, J., Schot, J., Geels, F.W., Loorbach, D., 2010. Transitions to Sustainable Development: New Directions in the Study of Long Term Transformative Change. Routledge, New York.

Hall, P., 2003. Aligning ontology and methodology in comparative research. In: Mahoney, J., Rueschemeyer, D. (Eds.), Comparative Historical Analysis in the Social Sciences. Cambridge University Press, Cambridge, New York, pp. 373-404.

Hekkert, M.P., Suurs, R.A.A., Negro, S.O., Kuhlmann, S., Smits, R.E.H.M., 2007. Functions of innovation systems: a new approach for analysing technological change. Technological Forecasting and Social Change 74, 413-432.

Hendriks, C., 2008. On inclusion and network governance: the democratic disconnect of Dutch energy transitions. Public Administration 86, 1009-1031.

Hodgson, G.M., Knudsen, T., 2004. Why we need a generalized Darwinism: and why a generalized Darwinism is not enough. Journal of Economic Behavior and Organization 61, 1-19.

Hoffman, A.J., 1999. Institutional evolution and change: environmentalism and the US chemical industry. Academy of Management Journal 42, 351-371.

Hofman, P.S., Elzen, B., 2010. Exploring system innovation in the electricity system through sociotechnical scenarios. Technology Analysis and Strategic Management 22,653-670.

Kemp, R., Schot, J., Hoogma, R., 1998. Regime shifts to sustainability through processes of niche formation: the approach of strategic niche management. Technology Analysis and Strategic Management 10, 175-196.

Konrad, K., Truffer, B., Voss, J., 2008. Multi-regime dynamics in the analysis of sectoral transformation potentials: evidence from German ultility sectors. Journal of Cleaner Production 16, 1190-1202.

Langley, A., 2007. Process thinking in strategic organization. Strategic Organization 5, 271-282.

Mahoney, J., 2000. Path dependence in historical sociology. Theory and Society 29, 507-548. 
March, J.G., 1991. Exploration and exploitation in organizational learning. Organization Science 2, 71-87.

Markard, J., Truffer, B., 2008. Technological innovation systems and the multi-level perspective: Towards an integrated framework. Research Policy 37, 596-615.

Merton, R.K., 1968. Social Theory and Social Structure. The Free Press, New York.

Nykvist, B., Whitmarsh, L., 2008. A multi-level analysis of sustainable mobility transitions: niche developments in the UK and Sweden. Technological Forecasting and Social Change 75, 1373-1387.

Pedriana, N., 2005. Rational choice, structural context and increasing returns: a strategy for analytic narrative in historical sociology. Sociological Methods \& Research 33, 349-382.

Pentland, B.T., 1999. Building process theory with narrative: from description to explanation. Academy of Management Review 24, 711-724.

Perez, C., 2002. Technological Revolutions and Financial Capital: The Dynamics of Bubbles and Golden Ages. Edward Elgar, Cheltenham.

Pettigrew, A.M., 1997. What is a processual analysis. Scandinavian Journal of Management 13, 337-348.

Porter, M., 1991. Towards a dynamic theory of strategy. Strategic Management Journal 12, 95-117, Winter Special Issue.

Raven, R.P.J.M., 2004. Implementation of manure digestion and co-combustion in the Dutch electricity regime: a multi-level analysis of market implementation in the Netherlands. Energy Policy 32, 29-39.

Raven, R.P.J.M, 2007. Co-evolution of waste and electricity regimes: multi-regime dynamics in the Netherlands (1969-2003). Energy Policy 35, 2197-2208.

Rip, A., Kemp, R., 1998. Technological change. In: Rayner, S., Malone, E.L. (Eds.), Human Choice and Climate Change, vol. 2. Battelle Press, Columbus, OH, pp. 327-399.

Røpke, I., 2009. Theories of practice: new inspiration for ecological economic studies. Ecological Economics 68, $2490-2497$.

Rothaermel, F.T., 2001. Complementary assets, strategic alliances, and the incumbent's advantage: an empirical study of industry and firm effects in the biopharmaceutical industry. Research Policy 30, 1235-1251.

Rotmans, J., Kemp, R., van Asselt, M., 2001. More evolution than revolution: transition management in public policy. Foresight $3,15-31$.

Schot, J.W., Geels, F.W., 2008. Strategic niche management and sustainable innovation journeys: theory, findings, research agenda and policy. Technology Analysis and Strategic Management 20, 537-554.

Seo, M.-G., Creed, W.E.D., 2002. Institutional contradictions, praxis, and institutional change: a dialectical perspective. Academy of Management Review 27, 222-247.

Sewell, J.H, 1996. Three temporalities: toward an eventful sociology. In: McDonald, T. (Ed.), The Historic Turn in the Human Sciences. The University of Michigan Press, pp. 245-280.

Shove, E., 2003. Comfort, Cleanliness and Convenience: The Social Organization of Normality. Berg, Oxford.

Shove, E., Walker, G., 2010. Governing transitions in the sustainability of everyday life. Research Policy 39, 471-476.

Skocpol, T., 1979. States and Social Revolutions: A Comparative Analysis of France, Russia and China. Cambridge University Press, Cambridge.

Smith, A., 2007. Translating sustainabilities between green niches and socio-technical regimes. Technology Analysis and Strategic Management 19, 427-450.

Smith, A., Stirling, A., Berkhout, F., 2005. The governance of sustainable socio-technical transitions. Research Policy 34 , 1491-1510.

Stirling, A., 2009. Direction, Distribution and Diversity! Pluralising Progress in Innovation, Sustainability and Development, STEPS Working Paper 32. STEPS Centre, University of Sussex, Brighton.

Sztompka, P., 1993. The Sociology of Social Change. Blackwell, Oxford UK.

Tushman, M.L, O’Reilly, C.A., 1996. Ambidextrous organizations: managing evolutionary and revolutionary change. Californa Management Review 38, 8-30.

Unruh, G.C, 2000. Understanding carbon lock-in. Energy Policy 28, 817-830.

Van Bree, B., Verbong, G.P.J., Kramer, G.J., 2010. A multi-level perspective on the introduction of hydrogen and battery-electric vehicles. Technological Forecasting and Social Change 77, 529-540.

Van den Bergh, J.C.J.M., Bruinsma, F.R. (Eds.), 2008. Managing the Transition to Renewable Energy: Theory and Practice from Local, Regional and Macro Perspectives. Edward Elgar, Cheltenham.

Van Driel, H., Schot, J., 2005. Radical innovation as a multi-level process: introducing floating grain elevators in the port of Rotterdam. Technology and Culture 46, 51-76.

Verbong, G.P.J., Geels, F.W., 2007. The ongoing energy transition: lessons from a socio-technical, multi-level analysis of the Dutch electricity system (1960-2004). Energy Policy 35, 1025-1037.

Verbong, G.P.J., Geels, F.W., 2010. Exploring sustainability transitions in the electricity sector with socio-technical pathways. Technological Forecasting and Social Change 77, 1214-1221. 